\title{
Pyramidal Cells, Patches, and Cortical Columns: a Comparative Study of Infragranular Neurons in TEO, TE, and the Superior Temporal Polysensory Area of the Macaque Monkey
}

\author{
Guy N. Elston and Marcello G. P. Rosa \\ Vision, Touch, and Hearing Research Centre, Department of Physiology and Pharmacology, The University of \\ Queensland, Queensland, 4072 Australia
}

\begin{abstract}
The basal dendritic arbors of layer III pyramidal neurons are known to vary systematically among primate visual areas. Generally, those in areas associated with "higher" level cortical processing have larger and more spinous dendritic arbors, which may be an important factor for determining function within these areas. Moreover, the tangential area of their arbors are proportional to those of the periodic supragranular patches of intrinsic connections in many different areas. The morphological parameters of both dendritic and axon arbors may be important for the sampling strategies of cells in different cortical areas. However, in visual cortex, intrinsic patches are a feature of supragranular cortex, and are weaker or nonexistent in infragranular cortex. Thus, the systematic variation in the dendritic arbors of pyramidal cells in supragranular cortex may reflect intrinsic axon projections, rather than differences in columnar organization. The present study was aimed at establishing whether cells in the infragranular layers also vary in terms of dendritic morphology among different cortical areas, and whether these variations mirror the ones demonstrated in su-
\end{abstract}

As a result of the pioneering anatomical studies of Lorente de Nó (1938) and the functional studies of Mountcastle and Powell (1959) and Hubel and Wiesel (1977), the idea of columnar organization has become a central tenet to the understanding of cortical function (for review, see Mountcastle, 1998. One of the primary determinants of the cortical column is the size of the dendritic arbors of its neurons (Szentágothai, 1983). Recently, several independent studies have shown that the dendritic arbors of supragranular pyramidal neurons vary between cortical areas. The basal dendritic arbors of pyramidal cells in the temporal and parietal lobes are generally larger, have more bifurcations, and have greater spine density, than those in the occipital lobe (Lund et al., 1993; Elston and Rosa, 1997, 1998a,b; Elston et al., 1999ac). Those in the frontal lobe are even larger and more spinous (Elston, 2000). The size of the basal dendritic arbors of layer III pyramidal cells in different cortical areas closely matches the size

Received Aug. 4, 2000; revised Sept. 25, 2000; accepted Oct. 4, 2000.

This work was supported by a project grant (990007) and a C.J. Martin Fellowship (G.N.E.) from the Australian National Health and Medical Research Council. We thank Dr. D. Vaney for providing the facilities for the cell injection experiments and Prof. J. Pettigrew and Dr. S. Ghosh for providing cortical tissue. We also thank Dr. D. Pow for providing his antibody to Lucifer yellow.

Correspondence should be addressed to Guy Elston, Instituto Cajal, Avenida Dr. Arce, 37, Madrid, 28002, Spain. E-mail: G.Elston@vthrc.uq.edu.au.

Dr. Rosa's present address: The Department of Physiology, Monash University, Clayton 3800, Victoria, Australia.

Copyright (C) 2000 Society for Neuroscience $\quad 0270-6474 / 00 / 200001-05 \$ 15.00 / 0$ pragranular cortex. Layer $\mathrm{V}$ pyramidal neurons were injected with Lucifer yellow in flat-mounted cortical slices taken from cytoarchitectonic areas TEO and TE and the superior polysensory area (STP) of the macaque monkey. The results demonstrate that cells in STP were larger, had more bifurcations, and were more spinous than those in TE, which in turn were larger, had more bifurcations and were more spinous than those in TEO. These results parallel morphological variation seen in layer III pyramidal neurons, suggesting that increasing complexity of basal dendritic arbors of cells, with progression through higher areas of the temporal lobe, is a general organizational principle. It is proposed that the differences in microcircuitry may contribute to the determination of the functional signatures of neurons in different cortical areas. Furthermore, these results provide evidence that intrinsic circuitry differs across cortical areas, which may be important for theories of columnar processing.

Key words: intracellular injection; Lucifer yellow; extrastriate; visual; cortex; dendrite; spine

of intrinsic axonal patches (Lund et al., 1993; Elston and Rosa, 1998a). However, whereas intrinsic patches are a striking feature of supragranular cortex, they are relatively indistinct or absent in infragranular layers in visual cortex (Rockland and Lund, 1983). Thus, the question then arose, does the systematic variation in the basal dendritic arbors of supragranular pyramidal cells solely reflect the patchy nature of intrinsic axon projections in these layers, or does it reflect a general trend for all pyramidal cells?

The morphology of supragranular and infragranular pyramidal cells within a given cortical areas have been quantified in a number of studies (Larkman and Mason, 1990; Larkman, 1991a,b; Elston et al., 1999d). However, these studies have been performed in primary sensory areas, which are arguably atypical.

This article is published in The Journal of Neuroscience, Rapid Communications Section, which publishes brief, peerreviewed papers online, not in print. Rapid Communications are posted online approximately one month earlier than they would appear if printed. They are listed in the Table of Contents of the next open issue of JNeurosci. Cite this article as: JNeurosci, 2000, 20:RC117 (1-5). The publication date is the date of posting online at www.jneurosci.org.

http://www.jneurosci.org/cgi/content/full/4809 


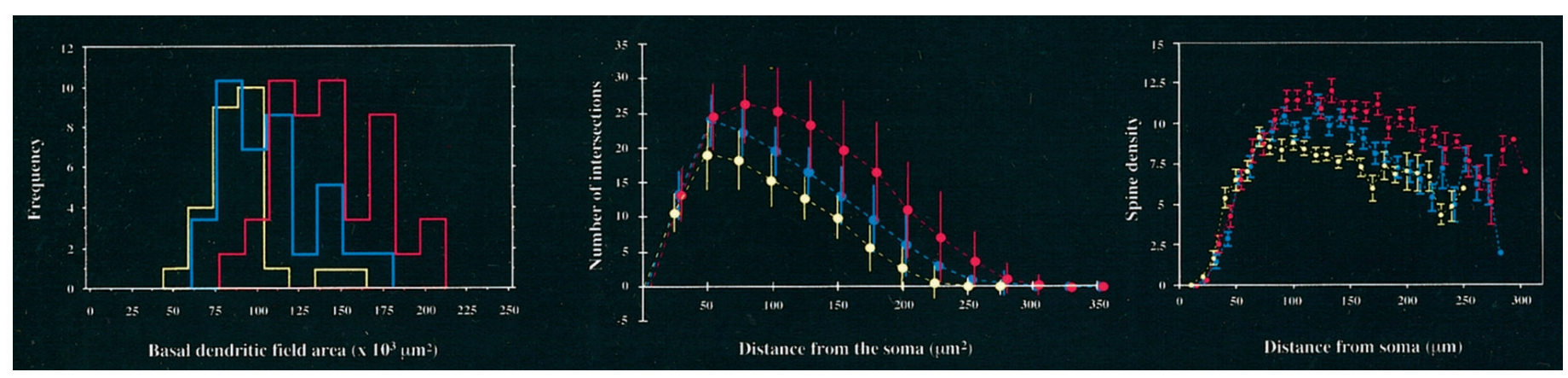

Figure 1. A, Frequency histograms of basal dendritic field areas of layer V pyramidal neurons in TEO (yellow), TE (blue), and STP (red) in the macaque monkey. B, Plots of Sholl analyses of the basal dendritic fields of layer V pyramidal neurons as a function of distance from the cell body. $C$, Plots of spine densities, as a function of distance from the cell body, of 20 randomly selected basal dendrites of different neurons in areas TEO, TE, and STP. Spine density varied as a function of distance from the soma and differed between visual areas. Error bars indicate SDs.

Our unpublished observations in association cortex suggest that the morphology of the basal dendritic arbors of supragranular and infragranular pyramidal cells may differ between different cortical areas. Infragranular pyramidal cell basal dendritic arbors may have double the number of spines of supragranular pyramidal cells within a given cortical area or may have a similar number of spines. Moreover, there may be considerable differences in the morphologies of supragranular versus infragranular pyramidal neurons in homologous areas of different species (Porter et al., 1991). In an effort to test whether the morphological variation reported for supragranular pyramidal neurons reflects overall differences in the geometry of cortical columns, we injected pyramidal neurons in layer $\mathrm{V}$ in three subdivisions of the temporal lobe: cytoarchitectural areas TEO and TE (von Bonin and Bailey, 1947) and the superior temporal polysensory area (STP) (Bruce et al., 1981; Boussaoud et al., 1991). These areas were chosen as supragranular cells therein show greater interareal differences through successive levels of the proposed hierarchies (for review, see Felleman and van Essen, 1991) than those seen in successive areas in the parietal (LIP, 7a) or occipital (V1, V2) lobes (cf. Elston and Rosa, 1997, 1998a; Elston et al., 1999a,b). Moreover, cortical areas TEO, TE, and STP are known to operate at different levels of analysis of visual information (Young, 1992, 1993; Gross et al., 1993; Rosa, 1997). We found that the basal dendritic fields of layer $\mathrm{V}$ pyramidal neurons become larger, more complex and have greater spine density with progression from TEO to TE and STP. These trends parallel those observed in supragranular pyramidal cells and suggest that circuitry may vary between cortical areas. The interareal differences in cell geometry may result in variation in columnar organization reported by others (Mountcastle, 1998).

\section{MATERIALS AND METHODS}

Methods of perfusion, slice preparation, cell injection, classification, morphological, and statistical analyses have been detailed in previous studies (Elston and Rosa, 1997, 1998a). Briefly, the right hemispheres of two adult macaque monkeys (Macaca fascicularis) were used in the present study. The protocol for these experiments was approved by the University of Queensland's Animal Experimentation Ethics Committee, which also monitored the welfare of the animals. The animals were deeply anesthetized with sodium pentobarbitol and perfused intracardially with physiological saline, which was followed by a solution of $4 \%$ paraformaldehyde in $0.1 \mathrm{~mol} / 1$ phosphate buffer, $\mathrm{pH}$ 7.2. Tissue was excised from areas TEO, TE, and STP, as shown in previous studies (Elston and Rosa 1998a; Elston et al., 1999a). Areas TEO and STP were taken from an 11-yr-old animal, and area TE was taken from a 16-yr-old animal. The tissue was prepared by "unfolding" the cortex, removing the white matter, and post-fixing between glass slides. Tangential sections
$(250 \mu \mathrm{m})$ were cut with the aid of a vibratome and prelabeled with the fluorescent dye 4,6 diamidino-2-phenylindole (DAPI; D9542, Sigma, St. Louis, MO). The section immediately underlying that which contained layer IV (which was easily distinguished by the size and density of granular cells: Elston and Rosa, 1997) was then selected for intracellular injection. Under UV excitation (341-343 nm) both the Lucifer yellow (LY)-filled microelectrode (back-filled with $0.1 \mathrm{~mol} / 1$ lithium chloride) and individual DAPI-labeled somata could be visualized. Neurons were injected by continuous negative current (up to $100 \mathrm{nA}$ ). The period of injection was determined visually by applying current until the individual dendrites of each cell could be traced to abrupt distal tips, and the dendritic spines were easily visible. After cell injection the tissue was processed with an antibody to Lucifer yellow (LY), at a concentration of 1:400,000 in stock solution [2\% bovine serum albumin (Sigma A3425), 1\% Triton X-100 (30632; BDH Chemicals, Poole, UK), and 5\% sucrose in $0.1 \mathrm{~mol} / \mathrm{l}$ phosphate buffer]. Anti-LY was detected by a species-specific biotinylated secondary antibody (Amersham, Arlington Heights, IL; RPN 1004; 1:200 in stock solution for $2 \mathrm{hr}$ ) and then a biotin-horseradish peroxidase complex (Amersham RPN1051; 1:200 in 0.1 mol/1 phosphate buffer). Labeling was revealed using 3,3'-diaminobenzidine (DAB) (Sigma D $8001 ; 1: 200$ in $0.1 \mathrm{~mol} / 1$ phosphate buffer) as the chromogen, allowing reconstruction of cell morphology in fine detail (Elston and Rosa, 1997, 1998a).

Neurons were drawn with the aid of a camera lucida, and basal dendritic field areas were determined by scanning the drawings of individual cells and using features of NIH Image software (National Institutes of Health Research Services, Bethesda, MD) to calculate the areas contained within a polygon that joined the outermost distal tips of the dendritic field. Sholl (1953) analysis was performed to determine the number of bifurcations in the basal dendritic arbors. Spines were drawn at high power $(100 \times$ oil immersion objective). Large numbers of cells were included for analyses, from each cortical area. Whereas there are obvious advantages in averaging aspects of cell morphology across large sample sizes to yield data on interareal phenotypic variation among pyramidal cells, the inclusion of large samples may have some inherent problems. For example, differences in the proportion of subpopulations of cells, which may have different morphologies (Matsubara et al., 1996), may bias the data. However, specific subpopulations of pyramidal cells (feedforward and feedback) in visual cortex show similar trends to those reported when cells are injected randomly (Elston and Rosa, 1999a,b). Moreover, it is only through the analyses of large populations of cells in many different cortical areas that differences marked systematic differences in pyramidal cell phenotype have been revealed. All slices in which we injected cells were photographed before cell injection, allowing for comparison before and after immunohistochemical processing to determine that shrinkage was negligible or nonexistent.

\section{RESULTS}

One hundred and eighty neurons were injected in layer $\mathrm{V}$ of cortical areas TEO, TE, and STP. Of these, 80 were included for analyses, because they had an unambiguous apical dendrite characteristic of pyramidal cells (for review, see Feldman, 1984; 


\begin{tabular}{lccc}
\hline Table 1. ANOVAs of basal dendritic field areas & & \\
Source & DF & Sum of squares & Mean square \\
\hline Between groups & 2 & $3.87 \times 10^{10}$ & $1.93 \times 10^{10}$ \\
Within groups & 77 & $5.70 \times 10^{10}$ & $7.40 \times 10^{8}$ \\
Total & 79 & $9.57 \times 10^{10}$ & 26.15 \\
& Post hoc $t$ tests (two-way unpaired) & $<0.05$ \\
\cline { 2 - 3 } & & TEO versus & TE versus \\
\cline { 2 - 3 } & TE & $p<0.05$ & $p<0.05$ \\
\hline
\end{tabular}

\begin{tabular}{|c|c|c|c|c|c|}
\hline Source & Sum of squares & D.F. & Mean squares & $\mathrm{F}$ ratio & Probability \\
\hline Area & $17.5 \times 10^{3}$ & 2 & $8.73 \times 10^{3}$ & 273.7 & $p<0.01$ \\
\hline Distance & $128.6 \times 10^{3}$ & 12 & $10.72 \times 10^{3}$ & 336.5 & $p<0.01$ \\
\hline Area $\times$ distance & $8.97 \times 10^{3}$ & 24 & 373.84 & 11.72 & $p<0.01$ \\
\hline \multirow[t]{5}{*}{ Within cells } & $24.27 \times 10^{3}$ & 761 & 31.89 & & \\
\hline & \multicolumn{3}{|c|}{ Post hoc pairwise comparison $t$ tests (correlated groups) } & & \\
\hline & & TEO versus & TE versus & & \\
\hline & $\mathrm{TE}$ & $p<0.05$ & & & \\
\hline & STP & $p<0.05$ & $p<0.05$ & & \\
\hline
\end{tabular}

Area (TEO, TE, and STP) by distance from cell body (25 $\mu \mathrm{m}$ intervals).

DeFelipe and Fariñas, 1992), were well filled, and their entire basal arbors were contained within the slice.

\section{Basal dendritic field areas}

As is the case for supragranular pyramidal neurons (Lund et al., 1993; Elston and Rosa, 1997, 1998a; Elston et al., 1999a-c), there were systematic variations in the size of the basal dendritic fields of neurons between visual areas (Fig. $1 A$ ). The basal dendritic arbors of pyramidal cells in area TEO $(n=27$; mean $\pm \mathrm{SD}$; $\left.89.8 \times 10^{3} \mu \mathrm{m}^{2} \pm 4.29 \times 10^{3} \mu \mathrm{m}^{2}\right)$, were smaller than those in area TE $\left(n=23 ; 108.2 \times 10^{3} \mu \mathrm{m}^{2} \pm 5.96 \times 10^{3} \mu \mathrm{m}^{2}\right)$, which were smaller than those in area STP $\left(n=30 ; 141.1 \times 10^{3} \mu \mathrm{m}^{2} \pm\right.$ $\left.5.48 \times 10^{3} \mu \mathrm{m}^{2}\right)$. An ANOVA revealed these differences to be significant, and post hoc $t$ tests showed that basal dendritic field areas were significantly different between all three cortical areas (Table 1).

\section{Complexity of the basal dendritic fields}

Not only did the basal dendritic fields of layer $\mathrm{V}$ pyramidal neurons become larger with rostral progression through visual areas of the temporal lobe, but their branching patterns also became more complex. The increasing complexity of the branching pattern can be seen in Figure $1 B$, where we plotted the results of Sholl analyses. In all three visual areas, the peak dendritic field complexity is located between 50 and $75 \mu \mathrm{m}$ from the cell body, beyond which the number of dendritic branches decreased. From Figure $1 B$ it can also be seen that the average peak complexities (defined as the maximum number of dendritic intersections on a given circle) of the basal dendritic fields varied between the different cortical areas. The overall trend was for increasing
Table 3. Statistical comparison of spine densities of the basal dendritic fields

Kruskal-Wallis test

\begin{tabular}{ll}
\hline Visual area & Mean rank \\
\hline TEO & 115.48 \\
TE & 158.54 \\
STP & 206.51 \\
\hline
\end{tabular}

Mann-Whitney $U$ tests

\begin{tabular}{lll}
\hline Comparison & $U^{\prime}$ & $z$ \\
\hline TEO versus TE & 6660.5 & $-3.35^{*}$ \\
TEO versus STP & 9342 & $-7.15^{*}$ \\
TE versus STP & 8179 & $-3.88^{*}$ \\
\hline
\end{tabular}

$\mathrm{DF}=2 ; n=325 ; H=52.128 ; p<0.0001$

$* p<0.001$.

dendritic field complexity from TEO to TE and from TE to STP. A two-way repeated measures ANOVA revealed significant differences in the complexity of the entire basal dendritic arbors between cortical areas. Post hoc $t$ tests revealed a significant difference between cells in all three areas (Table 2).

\section{Spine densities of the basal dendrites}

In conjunction with the increase in size and complexity of the basal dendritic fields, there was an increase in the peak spine density on the basal dendrites of neurons with rostral progression 
through the different visual areas. This is seen clearly in Figure $1 C$, in which we plotted spine density, as a function of distance from the cell body, for 20 randomly selected, horizontally projecting basal dendrites from each area. It is also clear, from Figure $1 C$, that spine density varies as a function of distance from the cell body, reaching a peak at $\sim 70-130 \mu \mathrm{m}$ from the soma, and tapering toward the distal tips. An ANOVA, and post hoc $t$ tests, confirmed that the difference in peak spine densities was significantly different between visual areas (Table 3). By combining data from the Sholl analyses and spine density, we calculated the total number of dendritic spines on the basal dendritic field for the "average" layer V pyramidal neuron in each visual area. On average, neurons in TEO had 1444 spines, those in TE had 2112 spines, and those in STP had 3324 spines.

\section{DISCUSSION}

Pyramidal neurons were intracellularly injected in layer $\mathrm{V}$ in tangential slices taken from cortical areas TEO, TE, and STP of the macaque monkey. Analyses of their basal dendritic arbors revealed differences in the branching patterns, spine densities, and absolute number of spines: there is a trend for more spinous cells with progression from TEO to TE, and STP. The increase in the number of spines (each of which receives at least one excitatory input: Jones and Powell, 1969) in the dendritic arbors of cells in "higher" cortical areas may be one of the strategies that allow complex processing reported in these areas (Gross et al., 1969; Perrett et al., 1982; Hikosaka et al., 1988), such as object recognition independent of the viewing perspective and polysensory integration.

The size of the basal dendritic arbors of supragranular pyramidal cells differs markedly across different cortical areas (Lund et al., 1993; Elston and Rosa, 1997, 1998a,b; Elston et al., 1999a-c; Elston, 2000). In many cortical areas, including areas TEO and TE, the basal dendritic fields of supragranular pyramidal neurons have been shown to be correlated with the size of intrinsic axonal patches (cf. Lund et al., 1993; Fujita and Fujita, 1996; Elston and Rosa, 1998a); however, this is yet to be established for area STP. The periodic organization of intrinsic axon patches has been described as nonexistent, or very indistinct, in the infragranular layers in primate visual cortex (Rockland and Lund, 1983). However, projections from area 46 to STP (TPOr) arborize in columns of 300-500 $\mu \mathrm{m}$ in width (Cusick et al., 1995), closely approximating the average size basal dendritic arbor of layer V pyramidal cells $(420 \mu \mathrm{m})$. The close match in the size of columnar projections to, and basal dendritic arbors of cells in, these cortical areas may be important for determining sampling strategies of cells and, consequently, their functional characteristics (Lund et al., 1993; Malach, 1994; Elston and Rosa, 1998a). Indeed, functional studies report columnar organization in temporal lobe areas (Fujita et al., 1992; Wang et al., 1996), with dimensions of the order of the basal dendritic arbors. However, not all projections to temporal cortex form columnar arborizations. For example, projections from many prefrontal areas to TE terminate preferentially in the supragranular layers (RempelClower and Barbas, 2000). Furthermore, projections from area TEO to area TE form band-like arborizations with varying anteroposterior profiles (Saleem et al., 1993) (for review, see Tanaka, 1997; Fujita, 1997; Yukie, 1997). Thus, individual neurons within cortical areas of the temporal lobe may sample the different sets of inputs according to different strategies, determined by geometrical relationships. The geometrical arrange- ment between axonal arborizations and dendritic arbors possibly reflect the functional requirements of the target cells.

Differences in the morphology and spine density of basal dendritic arbors of pyramidal cells in different cortical areas, and different layers of the same area, may affect the numbers of inputs that are integrated by (Elston et al., 1999a,b), and propagation of potentials through (Koch, 1999), their dendritic trees. Differing cell morphology may also be linked to the polarity of changes in synapse properties after electrical stimulation: the same experimental stimulus causes long-term depression in V1 cells but long-term potentiation in TE cells (Murayama et al., 1997). As infragranular and supragranular pyramidal cells also have markedly different apical dendrites, and the proportion of spines in the basal and apical components differs considerably (Larkman, 1991a), the relative "weight" of inputs also seems likely to influence the functional properties of infragranular versus supragranular cells (Sawatari and Callaway, 1996). Finally, backpropagation of action potentials into the dendritic arbors is reportedly influenced by a number of factors, including morphology, distribution of voltage-gated channels, and synaptic inhibition (for review, see Spruston et al., 1999). Thus, the markedly different morphologies of infragranular and supragranular pyramidal cells may affect the rate of decay of backpropogating potentials (for a review in axons, see Goldstein and Rall, 1974). Further experiments are required to establish to what extent morphological differences reported here affect the functional signatures of these cells.

\section{Conclusions}

The present results reveal differences in the morphology of the basal dendritic fields of infragranular pyramidal neurons in different cortical areas of the temporal lobe. These results parallel findings for supragranular pyramidal cells and support the view that pyramidal cells are markedly different across different regions. These findings raise the possibility that intra-areal columnar circuitry may be specialized for the functional requirements of a particular cortical area.

\section{REFERENCES}

Boussaoud D, Desimone R, Ungerleider LG (1991) Visual topography of area TEO in the macaque. J Comp Neurol 306:554-575.

Bruce CJ, Desimone R, Gross CG (1981) Visual properties of neurons in a polysensory area in superior temporal sulcus of the macaque. J Neurophysiol 46:369-384.

Cusick CG, Seltzer B, Cola M, Griggs E (1995) Chemoarchitectonics and corticocortical terminations within the superior temporal sulcus of the rhesus monkey: evidence for subdivisions of superior temporal polysensory cortex. J Comp Neurol 360:513-535.

DeFelipe J, Fariñas I (1992) The pyramidal neuron of the cerebral cortex: morphological and chemical characteristics of the synaptic inputs. Prog Neurobiol 39:563-607.

Elston GN (2000) Pyramidal cells of the frontal lobe: all the more spinous to think with. J Neurosci 20:(RC95)1-4.

Elston GN, Rosa MGP (1997) The occipitoparietal pathway of the macaque monkey: comparison of pyramidal cell morphology in layer III of functionally related cortical visual areas. Cereb Cortex 7:432-452.

Elston GN, Rosa MGP (1998a) Morphological variation of layer III pyramidal neurones in the occipitotemporal pathway of the macaque monkey visual cortex. Cereb Cortex 8:278-294.

Elston GN, Rosa MGP (1998b) Complex dendritic fields of pyramidal cells in the frontal eye field of the macaque monkey: comparison with parietal areas 7a and LIP. NeuroReport 9:127-131.

Elston GN, Rosa MGP (1999a) Morphological variation of MTprojecting cortical neurones in the marmoset monkey. Proc Aust Soc Neurosci 10:188.

Elston GN, Rosa MGP (1999b) Feedback cells in marmoset visual cortex: laminar position, morphology and topography of V1-projecting pyramidal neurones. Proc Int Brain Res Org 5:58.

Elston GN, Tweedale R, Rosa MGP (1999a) Cortical integration in the visual system of the macaque monkey: large scale morphological dif- 
ferences of pyramidal neurones in the occipital, parietal and temporal lobes. Proc R Soc Lond B Biol Sci 266:1367-1374.

Elston GN, Tweedale R, Rosa MGP (1999b) Cellular heterogeneity in cerebral cortex. A study of the morphology of pyramidal neurones in visual areas of the marmoset monkey. J Comp Neurol 415:33-51.

Elston GN, Tweedale R, Rosa MGP (1999c) Supragranular pyramidal neurones in the medial posterior parietal cortex of the macaque monkey: morphological heterogeneity in subdivisions of area 7. NeuroReport 10:1925-1929.

Elston GN, DeFelipe J, Arellano JI, González-Albo MC, Rosa MGP (1999d) Variation in the spatial relationship between parvalbumin immunoreactive interneurones and pyramidal neurones in rat somatosensory cortex. NeuroReport 10:2975-2979.

Feldman D (1984) Morphology of the neocortical pyramidal neuron. In: Cerebral cortex, Vol 1, Cellular components of the cerebral cortex (Peters A, Jones EG, eds), pp 123-200. New York: Plenum.

Felleman DJ, Van Essen DC (1991) Distributed hierarchical processing in primate cerebral cortex. Cereb Cortex 1:1-47.

Fujita I (1997) The inferior temporal cortex; columns and horizontal axons. In: The association cortex, structure and function (Sakata $\mathrm{H}$, Mikami A, Fuster J, eds), pp 247-258. Amsterdam: Harwood Academic.

Fujita I, Fujita T (1996) Intrinsic connections in the macaque inferior temporal cortex. J Comp Neurol 368:467-486.

Fujita I, Tanaka K, Ito M, Cheng K (1992) Columns for visual features of objects in monkey inferotemporal cortex. Nature 360:343-346.

Goldstein SS, Rall W (1974) Changes in action potential shape and velocity for changing core conductor velocity. Biophys J 14:731-757.

Gross CG, Bender DB, Rocha-Miranda CE (1969) Visual receptive fields of neurons in inferotemporal cortex of the monkey. Science 166:1303-1306.

Gross CG, Rodman HR, Gochin PM, Colombo MW (1993) Inferior temporal cortex as a pattern recognition device. In: Computational learning and recognition: proceedings of the 3rd NEC research symposium (Baum E, ed), pp 44-73. Philadelphia: Society for Industrial and Applied Mathematics.

Hikosaka K, Iwai E, Saito H, Tanaka K (1988) Polysensory properties of neurones in the anterior bank of the caudal superior temporal sulcus of the macaque monkey. J Neurophysiol 60:1615-1637.

Hubel DH, Wiesel TN (1977) Functional architecture of macaque visual cortex. Proc R Soc Lond B Biol Sci 198:1-59.

Jones EG, Powell TPS (1969) Morphological variations in the dendritic spines of the neocortex. J Cell Sci 5:509-529.

Koch C (1999) Biophysics of computation: information processing in single neurones. In: Computational neuroscience (Stryker M, ed). New York: Oxford UP

Larkman AU (1991a) Dendritic morphology of pyramidal neurones in the visual cortex of the rat: III. Spine distributions. J Comp Neurol 306:332-343.

Larkman AU (1991b) Dendritic morphology of pyramidal neurones in the visual cortex of the rat: I. Branching patterns. J Comp Neurol 306:307-319.

Larkman AU, Mason A (1990) Correlations between morphology and electrophysiology of pyramidal neurons in slices of rat visual cortex. I. Establishment of cell classes. J Neurosci 10:1407-1414.

Lorente De Nó R (1938) The cerebral cortex, architecture, intracortical connections and motor projections. In: Physiology of the nervous system (Fulton JF, ed), pp 291-325. London: Oxford UP.

Lund J, Yoshioka T, Levitt JB (1993) Comparison of intrinsic connec- tivity in different areas of macaque monkey cerebral cortex. Cereb Cortex 3:148-162.

Malach R (1994) Cortical columns as devices for maximizing neuronal diversity. Trends Neurosci 17:101-104.

Matsubara JA, Chase R, Thejomayen M (1996) Comparative morphology of three types of projection-identified pyramidal neurons in the superficial layers of cat visual cortex. J Comp Neurol 366:93-108.

Mountcastle VB (1998) The cerebral cortex. Cambridge, MA: Harvard UP.

Mountcastle VB, Powell TPS (1959) Neural mechanisms subserving cutaneous sensibility, with special reference to the role of afferent inhibition in sensory perception and discrimination. Bull Johns Hopkins Hosp 105:201-232.

Murayama Y, Fujita I, Kato M (1997) Contrasting forms of synaptic plasticity in monkey inferotemporal and primary visual cortices. NeuroReport 14:1503-1508.

Perrett DI, Rolls ET, Caan W (1982) Visual neurons responsive to faces in the monkey temporal cortex. Exp Brain Res 47:329-342.

Porter LL, Ghosh S, Lange GD, Smith TG (1991) A fractal analyses of pyramidal neurons in mammalian motor cortex. Neurosci Lett 130:112-116.

Rempel-Clower NL, Barbas H (2000) The laminar pattern of connections between prefrontal and anterior temporal cortices in the rhesus monkey is related to cortical structure and function. Cereb Cortex 10:851-865.

Rockland KS, Lund JS (1983) Intrinsic laminar lattice connections in primate visual cortex. J Comp Neurol 216:303-318.

Rosa MGP (1997) Visuotopic organization of primate extrastriate cortex. In: Cerebral cortex, Vol 12, Extrastriate cortex in primates (Rockland K, Kaas JH, Peters A, eds), pp 127-204. New York: Plenum.

Saleem KS, Tanaka K, Rockland KS (1993) Specific and columnar projection from area TEO to area TE in the macaque inferotemporal cortex. Cereb Cortex 3:454-464.

Sawatari A, Callaway EM (1996) Convergence of magno- and parvocellular pathways in layer $4 \mathrm{~b}$ of macaque primary visual cortex. Nature 380:442-446.

Sholl DA (1953) Dendritic organization in the neurons of the visual and motor cortices of the cat. J Anat 87:387-406.

Spruston N, Stuart G, Hausser M (1999) Dendritic integration. In: Dendrites (Stuart G, Spruston N, Hausser M, eds), pp 1-34. New York: Oxford.

Szentágothai J (1983) The modular architectonic principle of neural centers. Rev Physiol Biochem Pharmacol 98:11-61.

Tanaka K (1997) Columnar organization in the inferotemporal cortex. In: Cerebral cortex, Vol 12, Extrastriate cortex in primates (Rockland K, Kaas JH, Peters A, eds), pp 469-498. New York: Plenum.

von Bonin G, Bailey P (1947) The Neocortex of Macaca mulatta. Urbana, IL: University of Illinois.

Wang G, Tanaka K, Tanifuji M (1996) Optical imaging of functional organization in the monkey inferotemporal cortex. Science 272:1665-1668.

Young MP (1992) Objective analysis of the topological organization of the primate cortical visual system. Nature 358:152-154.

Young MP (1993) The organization of neural systems in the primate cerebral cortex. Proc R Soc Lond B Biol Sci 252:113-118.

Yukie M (1997) Organization of visual afferent connections to inferior temporal cortex, area TE, in the macaque monkey. In: The association cortex, structure and function (Sakata H, Mikami A, Fuster J, eds), pp 247-258. Amsterdam: Harwood Academic. 